\title{
Avaliação multidimensional da exclusão social em áreas rurais
}

\section{A multidimensional assessment of social exclusion in rural areas}

\author{
José Alex Nascimento Bento ${ }^{1}$ \\ Guillermo Gamarra Rojas ${ }^{2}$ \\ José de Jesus Sousa Lemos ${ }^{3}$ \\ Francisco Casimiro Filho ${ }^{4}$ \\ Jorge Luiz Schirmer de Mattos ${ }^{5}$
}

\section{Resumo}

O estudo teve como objetivo aferir os atuais indicadores de qualidade de vida dos agricultores de comunidades rurais selecionadas do município de Pentecoste, comparativamente ao que acontecia no município em 2010. Para tanto, utilizou dados primários, coletados de forma aleatória e com amostra cientificamente determinada. Os procedimentos metodológicos se concentram na utilização do Índice de Exclusão

1 Possui graduação em Ciências Econômicas pela Universidade Regional do Cariri (2012), mestrado em Economia Rural pela Universidade Federal do Ceará (2015) - Brasil - E-mail: josealex18@yahoo.com.br

2 Possui graduação em Agronomia pela Universidade Federal de Alagoas (1985), mestrado em Ciências Agrárias pela Escola de Agronomia da Universidade Federal da Bahia (1994) e doutorado em Botânica pela Universidade Federal Rural de Pernambuco (2002). Professor adjunto da Universidade Federal do Ceará - Brasil - E-mail: ggamarra@terra.com.br

3 Engenheiro agrônomo pela atual Universidade Federal Rural da Amazônia. Mestre em Economia Rural pela Universidade Federal do Rio Grande do Sul, doutor em Economia Rural pela Universidade Federal de Viçosa, pós-doutor em Economia dos Recursos Naturais e do Meio Ambiente pela Universidade da Califórnia. Professor titular na Universidade Federal do Ceará - Brasil - E-mail: lemos@ufc.br

4 Possui graduação em Engenharia Agronômica pela Universidade Federal do Ceará (1992), mestrado em Ciências (Economia Aplicada) pela Escola Superior de Agricultura Luiz de Queiroz da Universidade de São Paulo (1998) e doutorado em Economia Aplicada também pela Escola Superior de Agricultura Luiz de Queiroz da Universidade de São Paulo (2002). Professor Associado I da Universidade Federal do Ceará - Brasil - E-mail: casimiro@ufc.br

5 Graduado em Agronomia pela Universidade de Passo Fundo (1993), mestre em Zootecnia pela Universidade Federal de Larvas (1995), doutor em Zootecnia pela Universidade Federal de Viçosa (2001). Realizou estágio pós-doutoral na Universidad Pablo de Olavide, Sevilha Espanha (2014). É Professor Adjunto IV da Universidade Federal Rural de Pernambuco - Brasil -E-mail: js-mattos@hotmail.com 
Social (IES), que tem três indicadores e três subindicadores. Os indicadores são: passivo de educação (percentual da população maior de 15 anos analfabeta), passivo de renda (percentagem da população que sobrevive em domicílios com renda total variando de zero a no máximo dois salários mínimos) e passivo ambiental. Os três subindicadores são: privação de água encanada, privação de saneamento e privação de coleta sistemática de lixo. Os indicadores e subindicadores foram agrupados por meio de ponderação previamente realizada. Os resultados mostram que as carências são generalizadas em todas as comunidades estudadas. Chamam atenção os elevados percentuais de analfabetos que ainda perduram em boa parte delas, assim como merece especial preocupação os atuais níveis de renda e acesso aos ativos ambientais importantes, como água encanada, saneamento e coleta de lixo. A pesquisa conclui que não houve evolução dos indicadores de exclusão social condensados no IES em 2014 (ano da pesquisa) com os que foram contabilizados em 2010.

Palavras-chave: Passivos de educação e renda. Privações de ativos ambientais. Comunidades rurais.

\section{ABSTRACT}

This study aimed to assess the current quality of life indicators of farmers in selected rural communities in the municipality of Pentecost, compared to what happened in the city in 2010. In order to do this the search uses primary data collected randomly and with scientifically given sample. The methodological procedures focusing on the use of the Social Exclusion Index (HEI) which has three indicators and three subindicators. Indicators are education liabilities (percentage of the population 15 years illiterate); passive income (percentage of the population that lives in households with total income ranging from zero to a maximum of two minimum wages); environmental liabilities which consists of three sub-indicators of deprivation running water; sanitation deprivation and deprivation of systematic garbage collection. Indicators and sub-indicators were grouped by weight previously held. The results show that the deficiencies are widespread in all communities studied. Draws attention to the high illiteraterates that still lingers in many of them. As deserves particular concern the current levels of income and access to important environmental assets such as water, sanitation and garbage collection. The research concludes that there was no evolution of the indicators of social exclusion, condensed in the IES in 2014 (year of the survey) with those recorded in 2010.

Keywords: Liabilities of education and income; Deprivation of environmental assets; Rural communities. 


\section{Introdução}

A preocupação com a agricultura sustentável iniciou-se a partir da Primeira Guerra Mundial, basicamente na Europa e EUA, e alcançou sua maior influência nas últimas décadas do século $X X$, expandindo-se para todo o planeta. No Brasil, essa preocupação surgiu como consequência ao modo de desenvolvimento adotado na agricultura, advindo dos países industrializados, com o objetivo de modernização a partir da década de 1950, a partir do advento da "revolução verde". Esse caminho de desenvolvimento econômico postulava que, para a agricultura brasileira, caberiam os papéis de financiar o esforço de substituição de importação através da geração de divisas internacionais via exportação de produtos primários, produzir matérias-primas para a indústria nacional nascente, alimentar a crescente população urbana do país e gerar mercado para os bens advindos do emergente setor de transformação (FURTADO, 2005).

Decorrentes do processo de globalização da economia, a modernização e a industrialização da agricultura tornaram-se elementos importantes para a obtenção e manutenção de vantagens competitivas nos mercados de bens agrícolas. Diante dessa realidade, as atividades agrícolas, principalmente as agroindústrias, passaram a desempenhar papel de maior destaque no desenvolvimento econômico de áreas em processo de desenvolvimento. Isso porque contribuem para diminuir o subemprego e/ou o desemprego no setor urbano através da redução do êxodo rural e ocupam espaços onde outras indústrias não tenham condições de viabilidade.

O Ceará é o estado brasileiro que detém as maiores áreas e populações relativas no semiárido, oficialmente reconhecido pelo governo do Brasil. Atualmente, dos 184 municípios cearenses, 150 já estão reconhecidos como inseridos no semiárido. Esse fato faz com que a agricultura no estado, especialmente a de base familiar de sequeiro, seja bastante vulnerável às variações climáticas e, em decorrência, apresentem baixa resiliência (LEMOS, 2015). 
O papel do Estado de criar ações que viabilizem a convivência com o fenômeno da escassez hídrica tem se constituído num grande desafio, cujo objetivo é a busca do bem-estar socioeconômico das populações residentes no semiárido nordestino. Algumas das consequências da pobreza rural dessa região são provenientes da escassez de produção e de capacidade para sustentação da vida animal e vegetal nessas áreas castigadas (SILVA, 2008).

O município de Pentecoste faz parte dos 150 que estão incluídos no semiárido cearense e apresenta as características até aqui discutidas. Sua população, segundo o IBGE (2010), é de 35.400 habitantes, dos quais $60,44 \%$ são reconhecidos como população urbana e $39,56 \%$, como população rural. A densidade demográfica do município é de 25,68 hab/ $\mathrm{km}^{2}$ (IBGE, 2010).

Essa configuração demográfica, com boa parte da população ainda na zona rural, justifica-se pelo estímulo às atividades agrícolas na região. Suportadas através das águas do reservatório Pentecoste, essas atividades, em sua maioria lavouras tradicionais de subsistência, desenvolveram-se ao longo dos canais do projeto de irrigação do Departamento Nacional de Obras Contra as Secas (DNOCS) e das margens do açude (OLIVEIRA, 2009).

Neste estudo, tem-se como objetivo geral aferir, por meio do Índice de Exclusão Social (IES), os atuais indicadores da qualidade de vida dos agricultores de comunidades selecionadas do município de Pentecoste, enfatizando a sua capacidade de convivência no semiárido. A pesquisa também pretende avaliar se os IES estimados para as comunidades selecionadas de evoluíram nos últimos quatro anos, comparativamente ao que acontecia no município como um todo em 2010, segundo pesquisa realizada por Lemos (2012).

\section{Referencial teórico}

Nesta seção, serão discutidos os conceitos que foram relevantes na formatação empírica da pesquisa de campo. 


\subsection{Desenvolvimento rural}

Atualmente, não existe um conceito universalmente aceito sobre desenvolvimento, porém, é um tema discutido há dois séculos - e ainda bastante estudado e provocador de inúmeras dúvidas. Pesquisas históricas, teóricas e empíricas reduziram muito as indagações acerca desse conceito. Muitas ainda persistem e talvez tenham até aumentado (VEIGA, 2010).

O desenvolvimento foi visto como um problema científico no século XVIII, e suas causas podem ser explicadas. Conforme Souza (2008, p. 1): "o desenvolvimento econômico tem raízes teóricas e empíricas, originadas na maior parte das crises econômicas do sistema capitalista".

Sua discussão começou desde a fisiocracia na França, passando pelas escolas clássicas, neoclássicas e marxistas, prolongando-se até os dias atuais. Iniciou-se como sinônimo de crescimento econômico, e só no final do século $\mathrm{XX}$ começou-se a busca por um desenvolvimento econômico e social, em que tanto a acumulação de riquezas quanto as condições de vida da população em geral são importantes (SOUZA, 2008).

Durante a época em que desenvolvimento e crescimento econômico eram sinônimos, o modo de medir era considerar a evolução de indicadores tradicionais, como o Produto Interno Bruto (PIB) per capita. No entanto, quando se passou a considerar o conjunto de variáveis que seriam elementares à vida humana, como educação e serviços de saúde de qualidade, tornou-se evidente que indicadores econômicos sozinhos não conseguiriam representar o desenvolvimento, como antes era feito (UNITED NATIONS, 1994).

Por outro lado, Furtado (2004) sugeria que há diferença entre crescimento e desenvolvimento econômico, como se depreende da passagem a seguir.

[...] o crescimento econômico, tal qual conhecemos, vem se fundando na preservação dos privilégios das elites que satisfazem seu afã de modernização; já o 
desenvolvimento se caracteriza pelo seu projeto social subjacente. Dispor de recursos para investir está longe de ser condição suficiente para preparar um melhor futuro para a massa da população. Mas quando o projeto social prioriza a efetiva melhoria das condições de vida dessa população, o crescimento se metamorfoseia em desenvolvimento. (FURTADO, 2004, p. 484).

Segundo Sen (2000), a expansão da liberdade é o principal fim e o principal meio do desenvolvimento. Consiste na eliminação de tudo o que limita as escolhas e as oportunidades das pessoas. Destarte, o objetivo básico do desenvolvimento é alargar as liberdades humanas. $O$ processo de desenvolvimento pode expandir as capacidades humanas, as escolhas que as pessoas têm para experimentar vidas íntegras e participativas. Esse processo deve beneficiar todos os indivíduos, sem exceção, e fundamentar-se na inclusão de cada um deles. Essa é a abordagem de desenvolvimento que tem sido defendida por todos os Relatórios do desenvolvimento humano, desde o primeiro, em 1990 (VEIGA, 2000).

De acordo com essa abordagem, só existe desenvolvimento quando os benefícios do crescimento servem à ampliação das capacidades humanas, entendidas como o conjunto das alternativas que as pessoas podem ter na vida. E são quatro as mais elementares: ter uma vida longa e saudável, ser instruído, ter acesso aos recursos necessários para um nível de vida digno e ser capaz de participar da vida da comunidade (UNITED NATIONS, 1994).

Segundo Veiga (2000), inexiste a concepção de que "o desenvolvimento rural" seja um fenômeno concreto e separado do desenvolvimento urbano. O desenvolvimento é um processo complexo. Desse modo, pode-se apenas recorrer à simplificação para tentar explicá-lo, estudando separadamente o "lado rural do desenvolvimento".

Segundo Kageyama (2004), não há um consenso para a definição de "rural", mas existem pontos em comum nessa discussão teórica: a) rural não é sinônimo de agrícola nem tem exclusividade sobre este; 
b) o rural é multissetorial (pluriatividade) e multifuncional (funções produtivas, ambientais, ecológicas, sociais); c) as áreas rurais têm densidade populacional relativamente baixa; d) não há um isolamento absoluto entre os espaços rurais e as áreas urbanas. Redes mercantis, sociais e institucionais se estabelecem entre o rural e as cidades e vilas adjacentes.

A solução mais precisa acerca do que é rural encontra-se disponível através das pesquisas realizadas pelo IBGE (2002, p. 66): "Rural é a área externa ao perímetro urbano de um distrito, composta por setores nas seguintes situações de setor: rural de extensão urbana, rural povoado, rural núcleo, rural-outros aglomerados, rural-exclusive aglomerados".

De acordo com Van der Ploeg et al. (2000 apud KAGEYAMA, 2004), na Europa, o paradigma da modernização da agricultura, principal responsável pelo desenvolvimento agrícola da época, foi substituído por um novo, o de "desenvolvimento rural", no qual se inclui a busca de um novo modelo para o setor agrícola, com novos objetivos, como: a busca de sinergias com os ecossistemas locais, a valorização das economias de escopo em detrimento das economias de escala, e a pluriatividade das famílias rurais.

O desenvolvimento rural implica a criação de novos produtos e novos serviços, associados a novos mercados; procura formas de redução de custos a partir de novas trajetórias tecnológicas; tenta reconstruir a agricultura não apenas no nível dos estabelecimentos, mas em termos regionais e da economia rural como um todo; representa, enfim, [...] uma saída para as limitações e falta de perspectivas intrínsecas ao paradigma da modernização e ao acelerado aumento de escala e industrialização que ele impõe. Por isso, para esses autores, o desenvolvimento rural é um "processo multinível, multiatores e multifacetado. (VAN DER PLOEG et al., 2000 apud KAGEYAMA, 2004, p. 384).

Os países em desenvolvimento devem seguir um paradigma de desenvolvimento com base na parceria rural-urbana, pois os países 
pobres costumam ter a parte majoritária de sua população em áreas rurais, e a maior parte de seus recursos tendem a se concentrar no desenvolvimento industrial urbano, acelerando, assim, o êxodo rural e os problemas que ele traz para as cidades. Desse modo, o redirecionamento dos esforços desenvolvimentistas (e dos recursos das agências internacionais para o Terceiro Mundo), no sentido de tornar mais atrativas as áreas rurais como forma de reter a população mais pobre, e potenciais migrantes, é uma alternativa viável para esse problema (EPSTEIN; JEZEPH, 2001 apud KAGEYAMA, 2004).

\subsection{Breves considerações sobre a pobreza e exclusão social}

É notória a ênfase na luta contra a pobreza e a promoção do bemestar para os mais necessitados, e mesmo com esse caráter amplamente globalizado e generalizado, falta ainda encontrar maior consenso em torno do conceito e de como medir a pobreza. Ademais, os estudos sobre essa temática tendem a reduzir a complexidade do fenômeno. Desse modo, pode-se dividir em duas principais linhas de pensamento: de um lado, encontra-se uma análise objetiva, quantificável; de outro, uma abordagem subjetiva, qualitativa. Ambas não se excluem; ao contrário, complementam-se.

A primeira abordagem pode ser denominada de pobreza econômica, pois defende que a insuficiência de renda é o principal critério para identificação dos pobres. Os adeptos dessa concepção utilizam como metodologia de mensuração a formulação de linhas de pobreza.

Segundo Ravallion (1996), as linhas de pobreza são formuladas como um valor monetário pré-determinado capaz de aferir o bem-estar de um indivíduo em um lugar, num determinado período. Para Rocha (2003), as linhas de pobreza são formuladas a partir de estruturas de consumo observadas, cujo valor estaria associado ao mínimo indispensável para que um indivíduo se desenvolva adequadamente em determinada sociedade. 
Dentre as linhas de pobreza mais adotadas, destacam-se as concebidas pela utilização dos critérios relativo ou absoluto para mensuração da pobreza, obtendo-se, assim, uma linha de pobreza relativa e outra absoluta (ROCHA, 2003; SCHWARTZMAN, 2004, 2006).

Segundo esses autores, na primeira, há a definição dos indivíduos em estado de "pobreza relativa" - ou seja, a renda está muito abaixo da renda média de determinado país, estando estreitamente vinculada às questões de sobrevivência física. Já a segunda define indivíduos que possuem renda inferior ao necessário para consumir os bens considerados essenciais (cesta de alimentos que garanta uma ingestão diária mínima de calorias) para a vida das pessoas, portanto, relaciona as necessidades a serem satisfeitas em função do modo de vida estabelecido em determinada sociedade.

A segunda abordagem, com características subjetivas e qualitativas, surge como critica às limitações da formulação mais quantitativa e generalizada até então utilizada. Portanto, foi elaborada para superar a visão econômica da pobreza e agregar outros aspectos, como o social, o cultural e o político.

Contudo foi, a partir de 1990, com a apresentação do Índice de Desenvolvimento Humano (IDH) no primeiro Relatório de Desenvolvimento Humano, organizado pelo Programa das Nações Unidas para o Desenvolvimento (PNUD), que as concepções de bemestar e pobreza adquiriram uma perspectiva mais ampla, passando a ser considerados como fenômenos multidimensionais e multifacetados. O caráter explicativo exclusivamente pela renda cede espaço ao acesso a outras exigências básicas culturalmente definidas e indispensáveis ao desenvolvimento da potencialidade humana, além do exercício responsável da sua capacidade, sem menosprezar, indevidamente, seu ambiente natural (CARVALHO, 2008).

Há varias formas de tentar entender a pobreza nessa perspectiva subjetiva, destacam-se duas concepções que estabelecem possibilidades de definir este complexo e controvertido conceito: necessidades básicas insatisfeitas e privação das capacidades humanas. 
Na primeira abordagem, Rocha (2003) defende que o conceito de pobreza tem a possibilidade de ir além daquelas estabelecidas pela alimentação para incorporar uma gama mais ampla de necessidades humanas, como habitação, educação e saneamento. Portanto, podese definir de forma mais ou menos estrita o que são necessidades básicas, de acordo com a situação em cada sociedade. Observa-se que a abordagem das necessidades básicas avança na discussão de identificação da pobreza ao superar a visão monetária e aproximar-se de uma concepção mais ampla, de privação das capacidades (LEMOS, 2012).

Na segunda abordagem, a pobreza é vista como privação das capacidades, destacando-se o rompimento com a visão unidimensional, construída principalmente pelo economista indiano Amartya Kumar Sen, em seu livro intitulado Desenvolvimento como Liberdade, no qual afirma que a pobreza deve ser observada como privação de capacidades básicas, isto é, privação das liberdades substantivas dos indivíduos de levarem o tipo de vida que eles tenham direito. Para esse propósito, os indivíduos devem utilizar as liberdades instrumentais (políticas, econômicas, sociais, garantias de transparência e segurança protetora) para superar a pobreza (SEN, 2000).

De acordo com Martinez (1998), a pobreza se transforma em um círculo vicioso, que resulta da seguinte ideia: se é pobre o indivíduo que atende ao mínimo necessário para sua sobrevivência, impedindo o exercício de seus direitos, consequentemente, a ausência do exercício de seus direitos o impede de desenvolver suas capacidades, perpetuandose, portanto, a situação de pobreza.

Desse modo, reforça-se a visão de que quanto mais oportunidades forem disponibilizadas, mais desenvolvimento e menos privações vai se enfrentar. Para se aferir o desenvolvimento e a superação da pobreza, é preciso dar condições substanciais de liberdade, as quais devem ser fornecidas pelo Estado. Para essa concretização, é fundamental que se leve em conta as liberdades substantivas dos indivíduos (SEN, 2000).

Por fim, a concepção de pobreza como ausência das capacidades dos indivíduos, desenvolvida por Sen (2000), possibilitou o melhor 
entendimento da natureza e das causas da pobreza e estabeleceu bases mais consistentes para se identificar o que afeta as desigualdades individuais e atender às demandas de justiça social com participação social, subsidiando as políticas de combate à pobreza.

Nessa mesma concepção adotada por Sen (2000), Lemos (2012) defende que a melhor maneira de mensurar a pobreza é por meio dos indicadores de privação de serviços essenciais e de renda. Segundo ele, a linha de pobreza é um instrumento imaginário, que sofre oscilações da taxa de câmbio e, por isso, pode provocar distorções importantes no entendimento do fenômeno (LEMOS, 2012).

Ademais, para o mesmo autor, o conceito de exclusão social é muito mais amplo do que a pobreza mensurada pela renda. Observa-se que os cidadãos podem estar fora do mercado de trabalho e usufruir de serviços sociais essenciais, suavizando o estado de privação de renda. Por outro lado, eles podem estar inseridos no mercado de trabalho, recebendo rendimentos não suficientes para suas necessidades básicas, e ainda serem privados de serviços essenciais, os quais, para o autor, deveriam ser providos pelo Estado (LEMOS,2012).

A pobreza, vista na esfera econômica, representa obstáculo ao crescimento, pelo menos por dois motivos. Em primeiro lugar, por reduzir o mercado interno, restringindo os incentivos ao investimento; em segundo, porque atualmente o principal fator na produção não é mais a terra, não é mais o capital, nem o trabalho físico do homem, mas o conhecimento. Portanto, o desenvolvimento econômico e a superação da pobreza cada vez mais estão ligados pela quantidade de conhecimentos que os habitantes da região conseguirem mobilizar no trabalho (PEREIRA; SIGNER, 1992).

\section{Metodologia}

\subsection{Breve descrição do local}

O município de Pentecoste se encontra na mesorregião norte do estado do Ceará, mais precisamente na macrorregião de planejamento 
litoral oeste e na microrregião médio Curu, com área de $1.378,30 \mathrm{~km}^{2}$. A maior parte de seu relevo encontra-se na depressão sertaneja, sendo circundado ao norte pelos municípios São Gonçalo do Amarante, São Luís do Curu e Umirim; ao sul por Apuiarés, Paramoti, Caridade e Maranguape; ao leste por São Gonçalo do Amarante, Caucaia e Maranguape; e, por fim, ao oeste por Umirim, Itapajé, Tejuçuoca e Apuiarés (IPECE, 2013).

Segundo Aragão (1996), o município se destaca na produção de algodão, arroz, feijão, milho, coco, cana-de-açúcar, citros, acerola, banana, mamão e feijão, caracterizando-se como uma economia baseada principalmente na agricultura. Ademais, em menor escala e ordem decrescente, encontram-se outras atividades, como a pecuária, a aquicultura, o artesanato, a extração da cera de carnaúba e de minérios (rutilo, grafita e pirolusita) (ARAGÃO. 1996).

Todo esse desenvolvimento é demonstrado pelo Índice de Desenvolvimento Humano Municipal (IDHM) de Pentecoste, que em 2000 era de 0,457. Em 2010, chegou a 0,629. Com esse resultado, Pentecoste está em $82^{\circ}$ lugar no ranking estadual (IBGE, 2010; IPECE, 2013).

Com relação ao Produto Interno Bruto (PIB), em 2010, o município registrou PIB de $\mathrm{R} \$ 183.022 .000,00$, a preços de mercado, e PIB per capita de $\mathrm{R} \$ 5.168,00$. Dividindo-se o PIB por setor, a agropecuária teve participação de 9,47\%; a indústria, 21,33\%; e os serviços, $69,19 \%$ (IBGE, 2010; IPECE, 2013). Isso demonstra uma tendência de mudança na hegemonia histórica do setor agropecuário, passando este a ter importância econômica cada vez menor no município - tendência verificada para todo o estado do Ceará (Tabela 1). 
Tabela 1 - Participação dos setores e atividades econômicas no valor adicionado bruto a preços correntes, Ceará, 2007-2012.

\begin{tabular}{l|l|l|l|l|l|l}
\hline \multirow{2}{*}{$\begin{array}{l}\text { Setores/Atividades } \\
\text { econômicas }\end{array}$} & \multicolumn{6}{l}{$\begin{array}{l}\text { Participação no valor adicionado bruto a preços } \\
\text { correntes (\%) }\end{array}$} \\
\cline { 2 - 7 } & 2007 & 2008 & 2009 & 2010 & 2011 & 2012 \\
\hline Agropecuária & 6,19 & 7,06 & 5,10 & 4,16 & 4,70 & 3,38 \\
\hline Indústria & 23,57 & 23,61 & 24,51 & 23,71 & 22,22 & 22,84 \\
\hline Serviços & 70,24 & 69,33 & 70,38 & 72,13 & 73,08 & 73,78 \\
\hline Total & 100,00 & 100,00 & 100,00 & 100,00 & 100,00 & 100,00 \\
\hline
\end{tabular}

Fonte: IBGE (2015).

O estudo se localiza em comunidades selecionadas da zona rural do município. A hipótese subjacente é que os resultados encontrados para essas comunidades possam servir de pistas não apenas para o que está acontecendo nelas, mas ao que provavelmente ocorre na maioria das comunidades rurais do município e até dos demais municípios cearenses que se encontram no semiárido.

\subsection{Tamanho da amostra}

Conforme Cochran (1965), foi utilizada uma amostragem aleatória simples, em que, para a determinação do tamanho, seguiu-se o método para amostras de populações finitas, segundo fórmula a seguir:

$$
n_{1}=\frac{\sigma^{2} z^{2}}{d^{2}}
$$

$\mathrm{n}_{1}=$ tamanho da amostra para população infinita;

$\sigma^{2}=$ variância de uma das variáveis consideradas importantes;

$Z$ = valor tabelado da estatística para a distribuição normal, para o nível exigido de confiança;

$\mathrm{d}$ = desvio máximo do estimador médio em relação ao verdadeiro parâmetro. 
No entanto, considerando-se que a população é finita, faz-se necessário a seguinte correção:

$$
n_{0}=\frac{n_{1}}{1+\frac{n_{1}}{N}}
$$

Em que:

$\mathrm{n}_{0}=$ tamanho da amostra para população finita; $\mathrm{e}$

$\mathrm{N}=$ tamanho da população.

Desse modo, foram entrevistados 163 agricultores no município de Pentecoste, tomados aleatoriamente, distribuídos em 39 comunidades rurais. De acordo com o cálculo da amostra, em função do tamanho da população em estudo, foram considerados:

$$
\begin{aligned}
& z=1,98 \\
& \sigma^{2}=0,802
\end{aligned}
$$

Em que: $\sigma^{2}$ corresponde à variância da variável renda da família estudada.

Desse modo, obteve-se $d=0,14(14 \%)$ como parâmetro de desvio.

\subsection{Levantamento dos dados}

O levantamento dos dados primários foi realizado utilizandose um roteiro para o estudo do estabelecimento rural, no formato de questionário, composto por questões abertas e fechadas, para facilitar 0 processamento dos dados. Assim, as questões quantitativas e relativas aos aspectos econômicos foram fechadas, e as de cunho qualitativo, abertas.

Realizaram-se 163 entrevistas formais, com aplicação de questionário a estabelecimentos rurais (representando $6,06 \%$ do total das unidades de produção do município). Os trabalhos de levantamento de dados ocorreram nos meses de outubro a novembro de 2014 . O 
processamento e a sistematização dos dados primários coletados através dos questionários foram realizados através de uma planilha programada no aplicativo Microsoft Excel 2013. Para tal, também se utilizou o software SPSS 20.

Com relação aos dados secundários, foram utilizados dados bibliográficos disponíveis em instituições de ensino e pesquisa, como teses, dissertações e artigos científicos, além de dados estatísticos encontrados em órgãos especializados, como: Instituto Brasileiro de Geografia e Estatística (IBGE), Instituto de Planejamento do Ceará (IPLANCE), Empresa de Assistência Técnica e Extensão Rural do Ceará (EMATERCE), Secretaria de Desenvolvimento Agrário (SDA), Banco do Nordeste do Brasil (BNB), Empresa Brasileira de Pesquisa Agropecuária (EMBRAPA), Food and Agriculture Organization (FAO), dentre outros.

\section{4 Índice de Exclusão Social (IES)}

O Índice de Exclusão Social (IES) foi criado por Lemos (2012) para aferir os padrões de exclusão social, entendidos como sinônimo de pobreza. Esse índice sofreu mudanças desde sua criação, em 1995, até sua versão mais atualizada, em 2012. Nesta, é constituído de três indicadores: passivo de educação, passivo econômico e passivo ambiental (LEMOS, 2012).

O IES foi construído a partir da identificação das dificuldades que o IDH tem para mensurar padrões de bem-estar (ou de mal-estar) nas economias menos desenvolvidas, devido à falta de fidelidade nos dados colhidos sobre a variável "esperança de vida ao nascer". A amplitude do IES varia de zero (máxima exclusão) a 100\% (nenhuma exclusão).

Pode-se definir o IES por meio da seguinte equação:

$I E S_{i}=P_{i 1} Y_{i 1}+P_{i 2} Y_{i 2}+P_{i 3} Y_{i 3} ;$ onde $i=1,2, \ldots, n$

Em que:

$\mathbf{Y}_{\mathrm{i} 1}$ : PASSEDUC - é a percentagem da população com mais de 15 anos que se declarou analfabeta; 
$\mathbf{Y}_{\mathrm{i} 2}$ : PASSECON - é a percentagem da população que sobrevive em domicílios cuja renda varia de zero a, no máximo, dois salários mínimos.

$\mathbf{Y}_{\mathrm{i} 3}$ : PASSAMBI - é estimado por três indicadores:

a) PRIVAGUA - é a percentagem da população que sobrevive em domicílios sem acesso ao serviço de água encanada;

b) PRIVSANE - é a percentagem da população que sobrevive em domicílios que não têm saneamento adequado, entendido como sem acesso ao serviço de esgotamento sanitário, fossa séptica coletada ou rede de esgotamento sanitário;

c) PRIVLIXO - é a percentagem da população que sobrevive em domicílios que não têm acesso ao serviço de coleta sistemática de lixo doméstico, direta ou indiretamente;

$\mathrm{P}_{\mathrm{ij}}$ : constituem os respectivos pesos, cuja soma é igual a um, associado a cada indicador.

Os pesos associados aos indicadores do IES são oriundos de análise estatística multivariada, não permitindo que eles sejam influenciados pela subjetividade do seu criador. Os pesos emergem da relação existente entre os indicadores. Maiores detalhes acerca do procedimento metodológico, bem como da matriz de dados em que foram gerados os pesos, podem ser encontrados em Lemos (2012). Optouse por utilizar os mesmos pesos, para que seja possível estabelecer comparações entre os resultados encontrados nesta pesquisa e aqueles mostrados no trabalho em referência, que utilizou dados de Pentecoste publicados pelo Censo Demográfico do Brasil de 2010. Na Tabela 2, apresentam-se os pesos associados aos indicadores PASSEUC, PASSECON e PASSAMBI. 
Tabela 2 - Pesos para cada indicador do Índice de Exclusão Social, Brasil, 2012.

\begin{tabular}{lc}
\hline VARIÁVEIS & PESOS \\
\hline PASSEDUC & 0,35 \\
PASSECON & 0,35 \\
PASSAMBI & 0,30 \\
TOTAL & $\mathbf{1 , 0 0}$ \\
\hline
\end{tabular}

Fonte: Adaptado de Lemos (2012).

Na Tabela 3, apresentam-se os pesos estimados, tal como definidos em Lemos (2012), para os subindicadores do indicador PASSAMBI. A equação (4) define como esse indicador é obtido a partir dos subindicadores PRIVAGUA, PRIVSANE e PRIVLIXO.

PASSAMBI $=P_{i 5} Y_{i 5}+P_{i 6} Y_{i 6}+P_{i 7} Y_{i 7}$

Em que:

$$
\begin{aligned}
& \mathrm{Y}_{\mathrm{i} 5}=\text { PRIVAGUA; } \\
& \mathrm{Y}_{\mathrm{i} 6}=\text { PRIVSANE; } \\
& \mathrm{Yi}_{7}=\text { PRIVLIXO }
\end{aligned}
$$

Tabela 3 - Pesos utilizados para estimar o indicador PASSAMBI, Brasil, 2012.

\begin{tabular}{lc}
\hline Variáveis & Pesos \\
\hline PRIVAGUA & 0,35 \\
PRIVSANE & 0,35 \\
PRIVLIXO & 0,30 \\
Total & $\mathbf{1 , 0 0}$ \\
\hline
\end{tabular}

Fonte: LEMOS (2012). 
Assim, a equação (5) é a de definição do Índice de Exclusão Social (IES):

$$
\mathrm{IES}_{\mathrm{i}}=0,35 \mathrm{Y}_{\mathrm{i} 1}+035 \mathrm{Y}_{\mathrm{i} 2}+0,30\left(0,35 \mathrm{Y}_{\mathrm{i} 5}+0,35 \mathrm{Y}_{\mathrm{i} 6}+0,30 \mathrm{Y}_{\mathrm{i} 7}\right)
$$

Nesse contexto, os indicadores foram traduzidos em privações das capacidades induzidas pela ausência ou ineficiência do estado do Ceará e do município de Pentecoste na prestação de serviços essenciais, como acesso à educação, água encanada, saneamento e serviço de coleta sistemática de lixo. Esses fatores interagem com a capacidade produtiva das famílias rurais estudadas, induzindo-as a terem baixa renda.

\section{Resultados e discussão}

\section{1 Índice de Exclusão Social do município de Pentecoste-CE}

O estudo utilizou o Índice de Exclusão Social (IES) para aferir os padrões de exclusão social, entendidos como sinônimos de pobreza. Com sua utilização, pôde-se também hierarquizar as comunidades estudadas pelos padrões de exclusão social e estimar o percentual de excluídos em cada uma delas.

Na Figura 1 e Tabela 4, explicitam-se os percentuais da população socialmente excluída aferida pelo IES nas 39 comunidades rurais de Pentecoste amostradas. Apresentam-se também os passivos e as privações dos indicadores utilizados na estimação do IES das diferentes comunidades, relativos ao direto à educação (PASSEDUC), renda (PASSECON), serviços de água encanada (PRIVAGUA), saneamento (PRIVSANE) e coleta sistemática de lixo (PRIVLIXO). As últimas três privações são ponderadas para constituírem o passivo ambiental (PASSAMBI). 
José Alex Nascimento Bento, Guillermo Gamarra Rojas, José de Jesus Sousa Lemos, Francisco Casimiro Filho, Jorge Luiz Schirmer de Mattos

Figura 1: Índice de Exclusão Social nas comunidades pesquisadas em Pentecoste

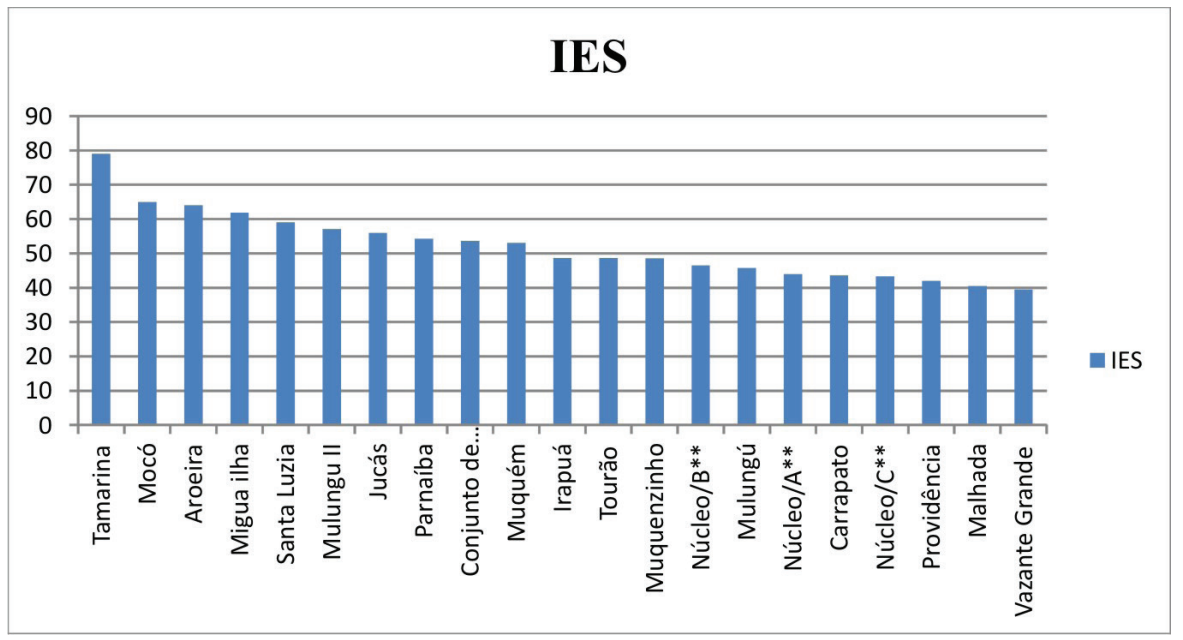

Fonte: Dados da pesquisa (2014). 
Tabela 4 - Exclusão social e privações de comunidades rurais de Pentecoste-CE, 2014.

\begin{tabular}{|c|c|c|c|c|c|c|c|}
\hline Comunidade & IES & PASSEDUC & PASSECON & PASSAMBI & Privagua & Privsane & Privlixo \\
\hline Tamarina & 79,00 & 100,00 & 100,00 & 30,00 & 0,00 & 0,00 & 100,00 \\
\hline Mocó & 65,00 & 40,00 & 75,00 & 82,50 & 100,00 & 50,00 & 100,00 \\
\hline Aroeira & 64,00 & 57,14 & 100,00 & 30,00 & 0,00 & 0,00 & 100,00 \\
\hline Migua ilha & 61,90 & 27,78 & 83,33 & 76,67 & 50,00 & 83,33 & 100,00 \\
\hline Santa Luzia & 59,10 & 25,00 & 100,00 & 51,25 & 25,00 & 100,00 & 25,00 \\
\hline Mulungu II & 57,10 & 37,50 & 100,00 & 30,00 & 0,00 & 0,00 & 100,00 \\
\hline Jucás & 56,00 & 21,05 & 83,33 & 65,00 & 0,00 & 100,00 & 100,00 \\
\hline Parnaíba & 54,30 & 14,29 & 100,00 & 47,50 & 40,00 & 10,00 & 100,00 \\
\hline $\begin{array}{l}\text { Conjunto de } \\
\text { Comunidades* }\end{array}$ & 53,60 & 8,33 & 78,57 & 77,12 & 50,00 & 84,62 & 100,00 \\
\hline Muquém & 53,10 & 18,18 & 77,78 & 65,00 & 100,00 & 0,00 & 100,00 \\
\hline Irapuá & 48,70 & 18,52 & 80,00 & 47,50 & 0,00 & 50,00 & 100,00 \\
\hline Tourão & 48,70 & 33,33 & 80,00 & 30,00 & 0,00 & 0,00 & 100,00 \\
\hline Muquenzinho & 48,60 & 26,09 & 57,14 & 65,00 & 100,00 & 0,00 & 100,00 \\
\hline Núcleo/B** & 46,50 & 7,14 & 100,00 & 30,00 & 0,00 & 0,00 & 100,00 \\
\hline Mulungú & 45,80 & 25,00 & 50,00 & 65,00 & 0,00 & 100,00 & 100,00 \\
\hline Núcleo/A** & 44,00 & 25,00 & 75,00 & 30,00 & 0,00 & 0,00 & 100,00 \\
\hline Carrapato & 43,60 & 43,33 & 55,56 & 30,00 & 0,00 & 0,00 & 100,00 \\
\hline Núcleo/C ${ }^{* *}$ & 43,30 & 23,08 & 75,00 & 30,00 & 0,00 & 0,00 & 100,00 \\
\hline Providência & 42,00 & 30,00 & 90,00 & 0,00 & 0,00 & 0,00 & 0,00 \\
\hline Malhada & 40,50 & 25,00 & 50,00 & 47,50 & 0,00 & 50,00 & 100,00 \\
\hline $\begin{array}{l}\text { Vazante } \\
\text { Grande }\end{array}$ & 39,50 & 0,00 & 57,14 & 65,00 & 71,43 & 28,57 & 100,00 \\
\hline Núcleo/D** & 36,80 & 9,52 & 57,14 & 45,00 & 0,00 & 42,86 & 100,00 \\
\hline Núcleo/F** & 36,80 & 14,29 & 50,00 & 47,50 & 50,00 & 0,00 & 100,00 \\
\hline Barrinha & 31,80 & 5,26 & 60,00 & 30,00 & 0,00 & 0,00 & 100,00 \\
\hline Núcleo/G** & 30,40 & 11,11 & 50,00 & 30,00 & 0,00 & 0,00 & 100,00 \\
\hline Núcleo/E** & 28,40 & 5,56 & 50,00 & 30,00 & 0,00 & 0,00 & 100,00 \\
\hline
\end{tabular}

* Pelo reduzido número de amostras para algumas comunidades e considerando a aproximação geográfica entre elas, criou-se o Conjunto de comunidades formadas pela união das seguintes comunidades circunvizinhas: Jardim; Coelho; Pedra Branca; Jiqui; Miranda de Baixo; Várzea do Gado; Capivara; Erva Moura; Xixá; Umari; Melancia; Fazenda Lagoa Velha; Sede-São Lourenço. ** Os núcleos A, B,C,D,E,F e G pertencem ao Perímetro Irrigado chamado Curu-Pentecoste.

Fonte: Dados da pesquisa (2014). 


\subsubsection{Passivo de educação (PASSEDUC)}

Os resultados mostrados na Tabela 4 sinalizam que o passivo de educação chega a 100\% na comunidade de Tamarina. Em 15 das comunidades estudadas, a taxa de analfabetismo da população maior de 15 anos (PASSEDUC) é superior a 20\%. Situação bastante difícil. É um dos maiores problemas a ser imediatamente encarado para reverter o atual quadro de exclusão social daquelas comunidades.

\subsubsection{Passivo econômico (PASSECON)}

O passivo econômico varia de $50 \%$ a $100 \%$, uma sinalização das dificuldades que as comunidades têm de fomentar renda para a sobrevivência. As principais fontes de renda das famílias provêm de atividades agrícolas com tecnologias ultrapassadas, que são vulneráveis às variações climáticas. Além disso, nota-se que o serviço de assistência técnica é carente nas comunidades. Assim, as atividades praticadas por aquelas famílias não são sustentáveis sob um ponto de vista econômico.

\subsubsection{Passivo ambiental (PASSAMBI)}

Os percentuais de privações ambientais variam de zero a $82,5 \%$. Contudo, a maioria apresentou essa privação de no mínimo 30\%. A pesquisa de campo mostra que as privações de acesso à água encanada e saneamento não muito elevadas. Contudo, o maior gargalo está no serviço de coleta sistemática de lixo. Em quase todas as comunidades a privação chegou a $100 \%$. Uma sinalização de que a carência do acesso a esses três ativos é regra nas comunidades estudadas (Tabela 4).

\subsubsection{Estimação do Índice de Exclusão Social (IES)}

Os IES estimados para os povoados estudados variaram de $28,4 \%$ a 79\%. Em trabalho de Lemos (2012), que teve como base os dados do Censo Demográfico de 2010, ficou demonstrado que o IES do município de Pentecoste era de $56,8 \%$. Na presente pesquisa, realizada quatro anos depois daquela do IBGE, em cinco das comunidades estudadas 
o IES supera o do município. Observa-se, ainda, que a maioria das comunidades estudadas teve IES superior a $40 \%$, sinalizando que, no geral, as áreas rurais pesquisadas encontram dificuldades de qualidade de vida para as famílias naqueles indicadores, tanto avaliados de forma individual como de forma ponderada no IES.

\section{Conclusão}

Os resultados encontrados sinalizam que o objetivo geral da pesquisa foi atingido, tendo em vista que os indicadores de comunidades selecionadas do município de Pentecoste foram perfeitamente identificados e quantificados na pesquisa.

Das evidências encontradas na pesquisa, depreende-se que grande parte dos agricultores familiares das comunidades pesquisadas do município encontrava-se em uma situação de extrema fragilidade social. Com a utilização do IES, puderam-se hierarquizar as comunidades estudadas, de acordo com os padrões de exclusão social. Além disso, foi possível, além da realização de um ranking, estimar o percentual de excluídos em cada uma delas.

Constataram-se elevados níveis de baixa escolaridade, traduzidos em elevadas taxas de analfabetismo na população maior de 15 anos. Constatou-se, ainda, que a maioria das populações daquelas comunidades sobrevive em domicílios que detêm níveis muito reduzidos de renda, tendo em vista que o indicador de passivo de renda é bastante elevado para a maioria delas.

Assim, estes dois indicadores, passivo de educação e passivo de renda, são críticos em praticamente todas as comunidades estudadas em Pentecoste.

No que concerne às privações de ativos essenciais, como água encanada, saneamento e coleta sistemática de lixo, constataramse indicadores também muito críticos. Com efeito, em apenas uma comunidade estudada há o serviço de coleta sistemática de lixo. Nas demais, o serviço não existe em praticamente todos os domicílios. 
Quanto à carência de saneamento, a pesquisa também mostrou que ela é generalizada nas comunidades estudadas, assim como também é praticamente generalizada a carência de acesso à água encanada.

No geral, a principal conclusão da pesquisa é que as comunidades rurais estudadas em Pentecoste apresentam carências generalizadas em todos os indicadores estudados, relativos à educação, renda e meio ambiente. Mostrou também que, comparativamente ao que havia sido previamente estimado em trabalho de Lemos (2012), que utilizou dados para o município como um todo, publicados pelo Censo Demográfico de 2010, as comunidades, também no geral, não apresentaram evolução quatro anos depois. Isso sugere que muitas providências não têm sido tomadas adequadamente para reverter o quadro de carências da zona rural do município.

Embora o trabalho tenha sido um estudo de casos selecionados em comunidades especificas de Pentecoste, pode-se inferir que, provavelmente, esses resultados dizem respeito à maioria da zona rural desse município e, quiçá, aos demais municípios do semiárido cearense. Obviamente, isso só poderá ser confirmado se forem realizadas pesquisas nessas outras comunidades, o que fica como sugestão.

\section{Referências}

ARAGÃO, R.B. Cronologia dos Municípios Cearenses. Fortaleza: Barraca do Escritor Cearense, 1996. p. 183-184.

CARVALHO, J. N. F. de. Pobreza e tecnologias sociais no extrativismo da carnaúba. 2008. 100f. Dissertação (Mestrado em Desenvolvimento e Meio Ambiente) - Universidade Federal do Piauí, Teresina, 2008.

COCHRAN, W.G. Técnicas de amostragem. Rio de Janeiro: Fundo de Cultura, 1965. 555p.

FURTADO, C. Os desafios da nova geração. Revista de Economia Política, São Paulo, v. 24, n. 4 (96), p. 483-486, out.-dez. 2004. 
FURTADO, C. Formação econômica do Brasil. São Paulo. Companhia Editora Nacional. 2005. Disponível em: <http:www.:///C:/ Users/JOSDEJ 1/AppData/Local/Temp/FURTADO_Celso_LIVRO_ Formacao_Economica_do_Brasil-4.PDF>. Acesso em: 22 dez. 2015.

INSTITUTO BRASILEIRO DE GEOGRAFIA E ESTATÍSTICA - IBGE. Censo demográfico 2000 e 2010. Disponível em: <www.ibge.gov.br>. Acesso em 22 jun. 2014.

. Documentação territorial do Brasil: Município de Pentecoste. Disponível em: <http://www. biblioteca.ibge.gov.br/dtbs_detalhes. php?id=515>. Acesso em 17 fev. 2015.

. Banco de Dados Agregados. Disponível em: <http://www. ibge.gov.br>. Acesso em 22 fev. 2015.

INSTITUTO DE PESQUISA E ESTRATÉGIA ECONÔMICA DO CEARÁ - IPECE.. Perfil básico municipal 2013 de Pentecoste. Disponível em: <http://www.ipece.ce.gov.br/publicacoes/perfil_basico/pbm-2013/ Pentecoste.pdf>. Acesso em: 20 jun.2014.

KAGEYAMA, A. Desenvolvimento rural: conceito e medida. Brasília: Cadernos de Ciência \& Tecnologia, v. 21, n. 3, p. 379-408, set./ dez. 2004. Disponível: <http://webnotes.sct.embrapa.br/pdf/cct/v21/ v21n3p379.pdf>. Acesso em: 30 out. 2011.

LEMOS, J.J.S. Mapa da Exclusão Social no Brasil: radiografia de um país assimetricamente pobre. 3. ed. Fortaleza: Banco do Nordeste Brasil, 2012.

LEMOS, J.J.S. Pobreza e vulnerabilidades induzidas no Nordeste e no semiárido brasileiros. 2015. 141f. Tese (Doutorado em Economia Rural ). - Universidade Federal do Ceará (UFC), Fortaleza, Ceará, 2015. Disponivel em: <http://www.lemos.pro.br/wp-content/uploads/ TESE-MONTADA-PARA-O-SITE.pdf >. Acesso em: 02 jan. 2016.

MARTÍNEZ, C.C. Pobreza urbana: problemas de ordem conceitual e implicação de política. Seminário sobre pobreza urbana, ALOP, Banco 
Mundial, 1998. Disponível em: <http://wbln0018.worldbank.org/LAC/ LACInfoClient.nsf/d29684951174975c85256735007fef 12/4c9a495cbd ec1d5385256804004d1e0a/\$FILE/Martinez.doc>. Acesso em: 15 jun. 2014.

OLIVEIRA, R. R. A.. Estudo da qualidade ambiental do reservatório pentecoste por meio do índice de estado trófico modificado. 2009. 140f. Dissertação (Mestrado em Desenvolvimento e Meio Ambiente) Programa de Pós-Graduação em Desenvolvimento e Meio Ambiente PRODEMA. Universidade Federal do Ceará, Fortaleza, 2009.

PEREIRA, H. B. C.; SIGNER, R.. Uma estratégia para a superação da pobreza na América Latina. Projeto regional para a superação da pobreza na América Latina. Rev. Estudos Avançados, São Paulo, v.6, n.16, p. 157-182, sept./dec., 1992. Disponível em: <http://www.scielo. br/pdf/ea/v6n16/v6n16a12.pdf>. Acesso em 1 jun. 2014.

RAVALLION, M. Issues in measuring and modeling poverty. World Bank: Policy Research Working, Paper 1615, jun 1996. Disponível em: <http:www.wordbank.org >. Acesso em 03 jun. 2014.

ROCHA, S. Pobreza no Brasil: afinal, de que se trata? Rio de Janeiro: Editora FGV, 2003.

SCHWARTZMAN, S. As causas da pobreza. Rio de Janeiro: Editora FGV, 2004.

, Redução da desigualdade, da pobreza e os programas de transferência de renda. Rio de Janeiro: Instituto de Estudos do Trabalho e Sociedade (IETS), 2006.

SEN, A. Desenvolvimento como liberdade. São Paulo: Companhia das Letras, 2000.

SILVA, R.M.A. Entre o combate à seca e a convivência com o semiárido: transições paradimáticas e sustentabilidade do desenvolvimento. Fortaleza -CE: Banco do Nordeste do Brasil. 2008 
SOUZA, Nali Jesus de. Desenvolvimento econômico. 5. ed. São Paulo: Atlas, 2008.

UNITED NATIONS. Human Development Report. New York. 1994.

VEIGA, J. E. da. Desenvolvimento Sustentável: o desafio o século XXI. Rio de Janeiro: Garamond, 2010.

A face rural do desenvolvimento: natureza, território e agricultura. Porto Alegre: Editora da UFRGS, 2000. 197 p.

Artigo recebido em: 04/07/2015

Aprovado em: 23/11/2015 